\title{
A Mathematical Model of Biomass Briquette Fuel Combustion
}

\author{
Jingxia Sui ${ }^{1}$, Xiang Xu${ }^{1,2}$, Bo Zhang ${ }^{1 *}$, Changjiang Huang ${ }^{2}$, Jinsheng Lv $^{1}$ \\ ${ }^{1}$ School of Energy and Power, Dalian university of technology, Dalian, China \\ ${ }^{2}$ Wen Zhou Special Equipment Inspection Center, Wenzhou, China \\ Email: zhangbo@dlut.edu.cn
}

Received March, 2013

\begin{abstract}
The numerical simulation model is proposed according to the characteristics of the biomass briquette fuels, which involves two main areas of interest: the solid combustion model in the bed and the out-of-bed gas combustion model. The contents and characteristics of 3 kinds of biomass and coals were experimentally tested. The biomass fuels compared with the coal fuel have the following characteristics: 1) Higher volatile content, lower fixed carbon content and calorific value; 2) Lower carbon content, higher oxygen content; 3) Lower ignition temperature, faster burning velocity. The discredited equations were established by the finite element analysis method, which analyzed the fuel endothermic process on the grate, while the out-of-bed gas combustion process was simulated by CFD. These two processes are strongly coupled. The results of the numerical simulation contain the steady state temperature distribution, oxygen distribution, carbon dioxide distribution and so on, which are used to judge burning effect and provide the correct furnace transformation method.
\end{abstract}

Keywords: Biomass; CFD; Simulation; Boiler; Combustion

\section{Introduction}

At present, the outbreak of the global energy crisis is making energy situation more serious in the world. M. Fatih Demirbas [1] pointed out that the biomass fuel is a renewable energy source and its importance would increase along with the national energy policy, focusing more on renewable sources. China is rich in biomass but its utilization is still lacking, causing a large amount of energy wasted. If these fuels could be effectively and efficiently used, China and even the world will benefit on the energy supplying and environmental protection.

Using the coal-fired boilers to burn the biomass fuels is an ineffective method of utilization, according to previous studies, which involved the following phenomenon, such as the combustion instability, heat congregation before furnace, the flame into fuel damper to ignite the fuels in the hopper, black smoke causing from bad air distribution, low thermal efficiency and poor environmental benefits. Therefore, careful study on biomass furnace design based upon the coal-fired's becomes important. The topic is to improve the biomass fuels combustion efficiency. Guo Y [2] pointed out that the coalfired boilers have to be improved to adapt to biomass fuel, because so many differences exist between the bio-

${ }^{*}$ Corresponding author. mass and the coal such as the fuel properties, the combustion phenomenon, the coking properties and the most suitable furnace structure.

Currently, many domestic and oversea experts are working on improving the biomass briquette combustion efficiency. Liang YD [3] pointed out that reducing the grate length, changing the front arch and the rear arch structures and setting the dust barrier wall are necessary ways to transform the existing coal-fired boiler. Lin P [4] studied the combustion characteristics of different biomass fuels, analyzed the main influence factors on combustion (fuel characteristics, shapes and sizes, and air distribution, etc.). Wang L [5] investigated on the coking problem in biomass combustion process, and discussed a variety of measures to reduce the ash. The main research methods on biomass combustion are experiments and simulations. Experimental studies can accurately and directly determine the burning effect, but the investment is large. Simulations have the advantages of simple, efficient and small investment, but it is idealized, so there is a big gap compared to the actual results. Therefore, more accurate numerical simulation methods become particularly important.

In this paper, the discrete equations were established by the finite element analysis method which analyzed the fuel endothermic process on the grate, and the results as 
the boundary condition of the out-of-bed gas combustion models, and finally the results of the gas combustion are displayed by CFD.

\section{Experiments}

\subsection{Analysis Experiments}

One kind of coal fuel and two kinds of woody biomass fuels are selected in this paper, and their physical properties were shown through industry analysis, elemental analysis and heat measurements. S1 is the coal fuel, S2 and S3 are the biomass fuels, and results are shown in Table 1 and Table 2.

The volatile content in the table refers to the dry ashfree basis volatile content. Fixed carbon content, moisture content and ash content refer to the content in the air dried basis. Comparing the biomass fuel with the coal fuel, it can be seen that:

- The biomass fuels contains a large proportion of volatile, a small amount of fixed carbon, so the combustion is more close to the gas combustion, which is clearly different from the fixed-carbon coal combustion.

- The biomass fuels contain more oxygen content and less carbon, so they need less theoretical air quantity.

- The biomass fuels have low calorie values, so when the same heat load required, the biomass fuel consumption is higher than the coal.

\subsection{The TGA Experimental}

Wu HX [7] made research on the pyrolysis performance, as well as their mixture, pointing out the different biomass at initial volatile releasing temperature and the first maximum peak temperature of co-pyrolysis increasing with more lignite in blend by thermo gravimetric analysis. It can be found that the differences between the biomass and the coal in thermal decomposition and combustion

Table 1. Industrial analysis.

\begin{tabular}{ccccc}
\hline \multirow{2}{*}{$\begin{array}{c}\text { Fuel } \\
\text { name }\end{array}$} & $\begin{array}{c}\text { Volatile } \\
(\%)\end{array}$ & $\begin{array}{c}\text { Fixed carbon } \\
(\%)\end{array}$ & $\begin{array}{c}\text { Moisture } \\
(\%)\end{array}$ & $\begin{array}{c}\text { Ash } \\
(\%)\end{array}$ \\
\hline S1 & 6.89 & 83.14 & 7.75 & 3.21 \\
S2 & 80.13 & 17.67 & 9.87 & 1.32 \\
S3 & 83.61 & 14.64 & 10.14 & 0.58 \\
\hline
\end{tabular}

Table 2. Element analysis and the calorie value.

\begin{tabular}{ccccccc}
\hline $\begin{array}{c}\text { Fuel } \\
\text { name }\end{array}$ & $\begin{array}{c}\mathrm{C} \\
(\%)\end{array}$ & $\begin{array}{c}\mathrm{H} \\
(\%)\end{array}$ & $\begin{array}{c}\mathrm{O} \\
(\%)\end{array}$ & $\begin{array}{c}\mathrm{N} \\
(\%)\end{array}$ & $\begin{array}{c}\mathrm{S} \\
(\%)\end{array}$ & $\begin{array}{c}\mathrm{LCV} \\
\mathrm{MJ} / \mathrm{kg}\end{array}$ \\
\hline S1 & 84.81 & 1.97 & 8.93 & 0.94 & 0.13 & 30.49 \\
S2 & 48.56 & 0.47 & 49.28 & 0.24 & 0.12 & 18.5 \\
S3 & 48.78 & 1.15 & 49.3 & 0.09 & 0.11 & 18.47 \\
\hline
\end{tabular}

by making the TGA experiments in this paper. The experimental conditions were that the temperature rise rate of 20 degrees per minute in an air atmosphere. The experimental results are shown in Figure 1.

On the basis of the TGA experimental results, it could be seen that:

- Comparing to the coal fuel, the extrapolated onset and decomposition temperatures are $200^{\circ} \mathrm{C}$ lower, and the termination temperature is only a half, which means that the biomass fuel is easier to be decomposed and its ignition temperature is lower.

- All the fuels contain higher moisture, so at the beginning of the experiment, there is precipitation of the moisture and the fuel quality reduced, and then their mass close to the same stage in a period of time.

- As far as biomass fuels, the extrapolated onset temperature is around $250^{\circ} \mathrm{C}$, the decomposition temperature is of $50 \%$, around $350{ }^{\circ} \mathrm{C}$ and epitaxial terminate temperature around $500{ }^{\circ} \mathrm{C}$.

\section{The Numerical Simulation of the Biomass Particles}

Many numerical researches related to the combustion simulations have been carried out. For example, Chaouki Ghenai [6] directly simulated pulverized biomass mixed with pulverized coal combustion, providing selections of models and drawing the conclusion that increasing the residence time and enhancing vortex could improve the combustion efficiency. The shape of the fuel has an important effect on the combustion, so the simulation method of the pulverized fuels combustion is not suitable for the biomass briquette fuels. There are three ways to solve the above problem.

Firstly, a simple approach is to use inlet conditions for the top of the fuel bed based on the experimental measurements [8].The inlet conditions contain the gas temperature, speed and species. Secondly, a more complex method is to develop a separate sub-model that calculates the temperature, velocity and species at the top of the

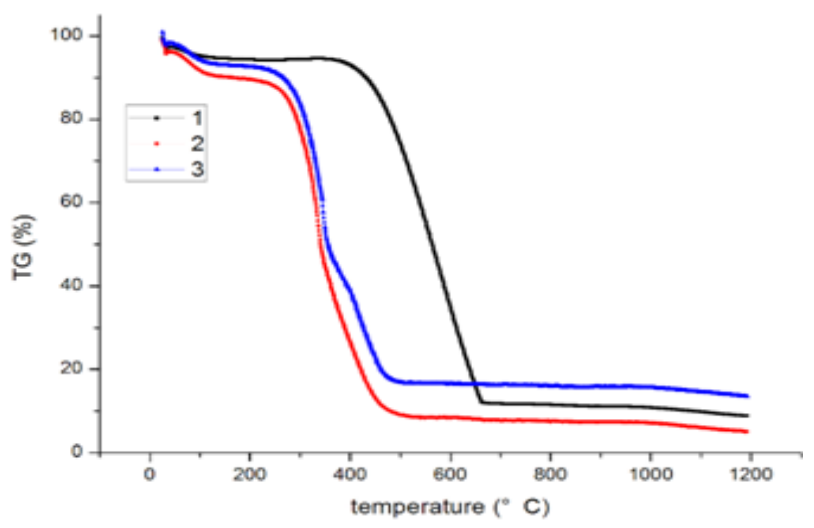

Figure 1. Three fuel TGA experiments. 
fuel bed. The CFD code can then be coupled with the bed sub-model, and the radioactive flux emitted by the flame and furnace walls to the top fuel layer, fed back for the next interaction of the bed model [9].The third type of approach, which is not so commonly adopted, is to define a user defined sub-routines (UDF) within the Fluent code. This code contains the essential details to characterize the solid and gas phase interactions $[10,15]$.

In this paper, the second approach is combined with the third. The mathematical model consists of two submodels: one model for the burning bed of biomass briquette, and the other model for the gas combustion in the furnace above the bed. The fuel is continuously lost mass during moving in the bed (moisture evaporation, devolatilization and char combustion). The conditions for the top of the bed are calculated from overall heat and mass balances of the fuel components and the primary air velocity. To simulate the gas phase reactions within the full geometry of a biomass furnace in CFD, a model for turbulence flow and radiation transfer is need. The inlet boundary condition based on the conditions for the top of the bed, is achieved by a user defined sub-routines (UDF) within the CFD code. The modeling schematic view of the model is shown in Figure 2:

\subsection{The Combustion Model on the Grate}

In order to model the heat and mass transfer process in the bed, the fuel in the bed along with the grate movement is discredited, and the mass conservation equations for each element are based on moisture evaporation, volatile release and char combustion. Heat conservation equations for each element are based on radioactive heat transfer, convective heat transfer and combustion heat production. The interaction between the gas and solid phase occurs through the relevant source terms in the conservation equation. The mass and energy conversion relationship for an element is shown in Figure 3.

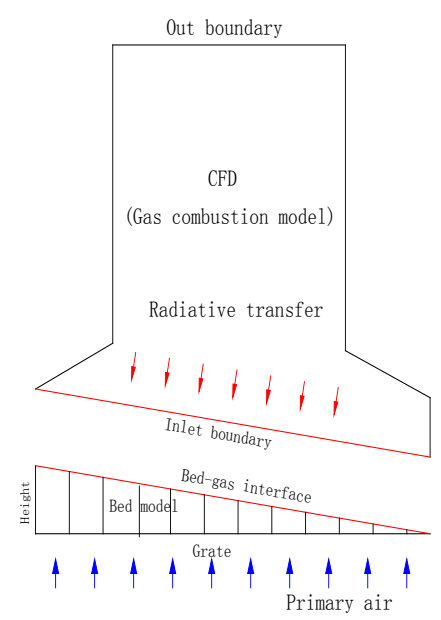

Figure 2. Numerical simulation model.

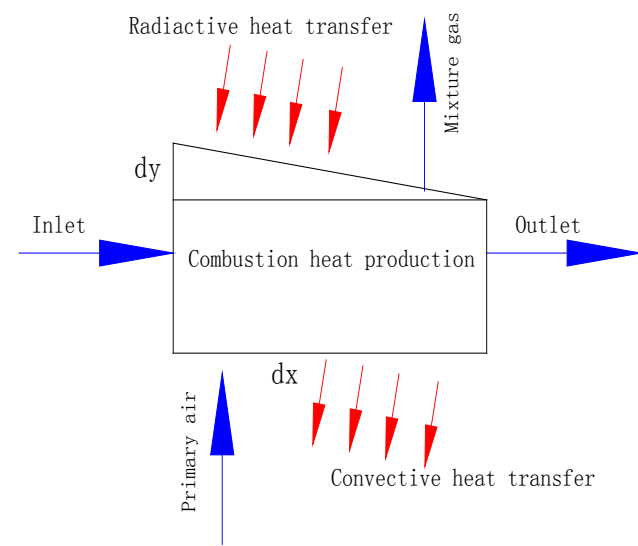

Figure 3. The computing element.

It is assumed that the fuels in the bed are continuous porous medium, the bulk density of the fuel and the bed voidage remain unchanged; the heat transfer in the fuel height direction is ignored and the volatiles in the release process have no combustion reaction. The primary air is evenly distributed. According to the formulas about moisture evaporation rate and volatile release rate [11, 12 ], and combined with the combustion characteristics in this paper, the following discrete equations can be got.

1) Char without oxidation:

a) Mass conservation,

$$
\text { pudy / (ydx) }=-\operatorname{Revp}-\mathrm{R}_{\mathrm{V}}
$$

b) Energy conservation,

$$
\begin{aligned}
\rho \mathrm{pu} d \mathrm{~T} /(\mathrm{dx})= & -\mathrm{S}_{\mathrm{a} 1} \mathrm{~h}_{\mathrm{s}}{ }^{\prime}\left(T-\mathrm{T}_{\mathrm{g}}\right) / 1000 \\
& +\mathrm{t} \delta\left(\mathrm{T} 2 \mathrm{~T}-{ }^{4}\right) / 1000
\end{aligned}
$$

2) Char oxidation:

a) Mass conservation,

$$
\text { pudy / }(\mathrm{ydx})=-\operatorname{Revp}-\mathrm{R}_{\mathrm{V}}-\mathrm{R}_{\mathrm{C}(\mathrm{s})}
$$

b) Energy conservation,

$$
\begin{aligned}
& \text { pu2dT / (dx) }=-\mathrm{S}_{\mathrm{a} 1} \mathrm{~h}_{\mathrm{s}}{ }^{\prime}\left(\mathrm{T}-\mathrm{T}_{\mathrm{g}}\right) / 1000 \\
& +\varepsilon \delta\left({ }_{\mathrm{a}} 2 \mathrm{~T}_{\mathrm{l}}^{4}-\mathrm{T}^{4}\right) / 1000+\mathrm{W}_{\text {char }}
\end{aligned}
$$

3) The rate of moisture evaporation can be express as: a) when $\mathrm{T}<100{ }^{\circ} \mathrm{C}$,

$$
\text { Revp }=\text { Sahs } \quad\left(\bigotimes_{\mathrm{w}, \mathrm{s}}-\mathrm{C}_{\mathrm{w}, \mathrm{g}}\right.
$$

b) when $\mathrm{T} \geqslant 100^{\circ} \mathrm{C}$,

$$
\begin{gathered}
\operatorname{Revp}=\mathrm{Q}_{\mathrm{cr}} / \mathrm{H}_{\text {evp }} \\
\mathrm{Q}_{\mathrm{cr}}=\mathrm{S}_{\mathrm{a} 1 \mathrm{~g}} \mathrm{~g} \dot{\mathrm{g}}\left(\mathrm{T}_{\mathrm{g}}-\mathrm{T}\right)+\mathrm{S}_{\mathrm{a} 2} \quad{ }_{1}^{4}-{ }^{4}
\end{gathered}
$$

4) The rate of volatile devolatisation can be express as,

$$
\mathrm{R}_{R} \mathrm{Y}=\operatorname{Avexp} \quad\left(-\mathrm{E}_{\mathrm{v}} /(\mathrm{RT})\right)
$$


5) The rate of char oxidation can be express as,

$$
\mathrm{R}_{\mathrm{C}(\mathrm{s})}=\mathrm{C}_{\mathrm{o} 2} /\left(1 / \mathrm{k}_{\mathrm{r}}+1 / \mathrm{k}_{\mathrm{d}}\right)
$$

The moisture content and volatile content,

$$
\begin{gathered}
\mathrm{C}_{\mathrm{w}, \mathrm{s}}=\mathrm{C}_{\mathrm{w}, \mathrm{s}}-\mathrm{SahsC}_{\mathrm{w}, \mathrm{s}} \mathrm{dt} \\
\mathrm{Y}_{\mathrm{V}} \propto \mathrm{Y}_{\mathrm{V}} \mathrm{A}-\exp \mathrm{v}_{\mathrm{V}} \quad\left(-\mathrm{E}_{\mathrm{V}} /(\mathrm{RT})\right) \mathrm{dt}
\end{gathered}
$$

where $\rho$ is the bulk density of the fuel, $u$ is the speed of the grate, Sa is the particle surface area, hs is the connective mass transfer coefficient between solid and gas, $\mathrm{C}_{(\mathrm{w}, \mathrm{s})}$ is the moisture concentration at solid surface, $\mathrm{C}_{(\mathrm{w}, \mathrm{g})}$ is the moisture concentration in the gas phase, $\mathrm{Y}_{\mathrm{V}}$ is the mass fraction of volatile matter remaining in biomass briquette, $\mathrm{Av}$ is the pre-exponential factor, Ev is the activation energy, $\mathrm{R}$ is the gas constant, $\mathrm{S}_{\mathrm{a} 1}$ is the particle convective heat transfer surface area, $S_{a 2}$ is the particle radioactive heat transfer surface area, $\mathrm{T}_{\mathrm{g}}$ is the primary air temperature $T_{1}$ is the furnace temperature, $T$ is the fuel temperature.

Several results can be got according to the above calculation, such as the fuel height, the moisture and volatile content, the fuel temperature, the mass fraction in the mixture, the temperature and the velocity about the mixture, the mixed gas temperature and velocity. All the results as the inlet boundary conditions to the Fluent to simulate the gas phase.

\subsection{Out of Bed Gas Combustion Model}

Volatile combustion occurs in the gas phase, and Fluent was selected to simulate the gas combustion. To simulate the gas phase reactions within the full geometry of a biomass furnace, models for turbulence and radiation need to be selected. To model the turbulent interactions within the boiler, the standard Realizable k-epsilon Model was adopted. Radiation heat transfer in biomass furnace was modeled with the $\mathrm{P} 1$ radiation model [12].

The kinetics of gas phase reaction and the mixing rate of oxidizer and fuel are the dominant factors to influence the gas combustion rate. The gas phase reactions are kinetically fast above the fuel bed, where the temperature is high and the reactions quickly, leading to the combustion is only controlled by the mixing rate The rate of a reaction in particular cell is determined by the minimum limiting value between the kinetics and the mixing rate[13,14].

\section{Results Analysis}

The simulation model is used to calculate the biomass briquette combustion in the grate. Several results can be got according to the calculation on the solid combustion in the bed, which are shown in Figure 4.

The figure shows the mixture fraction distribution and temperature distribution above the grate. These results would be as the boundary condition for the furnace simulation.

The simulation on biomass combustion in the two different furnaces under the condition that keep the fuel characteristic, the grate speed, the air temperature, flow rate and velocity constant. The simulation results about the biomass burning in the coal-fired boiler are shown in Figure 5, contain the temperature distribution and the mass fraction of $\mathrm{O}_{2}$.
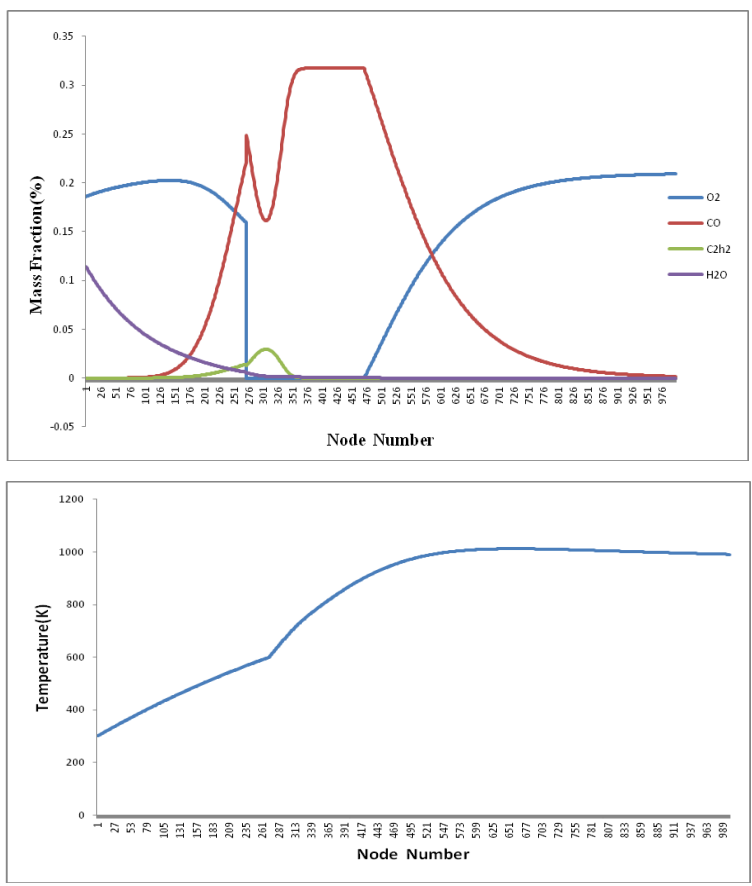

Figure 4. The solid combustion results.
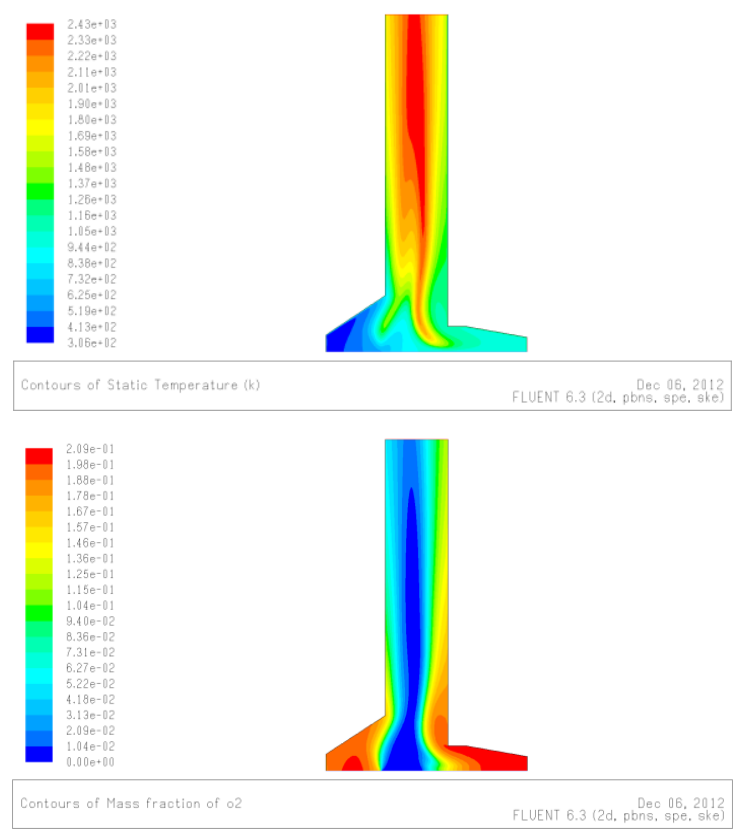

Figure 5. The combustion results of coal-fired boiler. 

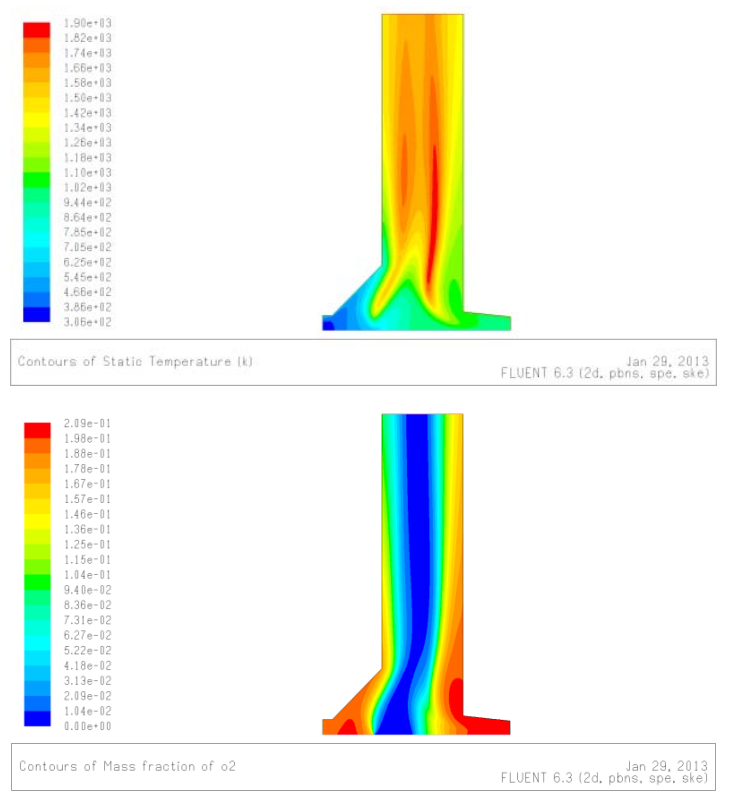

Figure 6. The combustion results of transformation boiler.

The simulation results shows that the biomass burning in the coal-fired boiler have some problems such as the high temperature.

The simulation results about the transformation boiler are shown in Figure 6, contain the temperature distribution and the mass fraction of $\mathrm{O}_{2}$. Compared with the coal-fired boiler, the arch angle increase and the front arch covered area decrease.

Through the simulation results, the conclusion can be drawn:

1) The oxygen is likely lack to burn the volatiles in the middle of furnace.

2) The combustion of the biomass is closer to the gas combustion because the fuel is about around $80 \%$ volatile, which is have a huge different from the coal.

3) The flame position in the furnace clearly down after the transformation, which improved the convective heat transfer of the flue gas and the efficiency of the boiler.

4) A large space to ensure the stable and complete combustion of volatile gases after the transform the furnace structures are needed, but the transformation weakens the disturbance of the mixture.

\section{REFERENCES}

[1] M. F. Demirbas, M. Balat and H. Balat, "Potential Contribution of Biomass to the Sustainable Energy Development," Energy Conversion and Management, Vol. 50, No. 7, 2009, pp. 1746-1760. doi:10.1016/j.enconman.2009.03.013

[2] Y. Guo and B. Q. Liu, "Analysis and Improvement of Flame Detection System about Power Supply Design De- fects,” Boiler Technology, 2012.

[3] Y. D. Lliang, Z. G. Li and Q. Z. Niu, "Biomass Fuels and Biomass Boiler," Industrial Boiler Modern Design and Development, China's Quality Press, Beijing, 2011, pp. 123-164.

[4] P. lin, "Experimental Study on the Biomass Combustion Character in Stoker-Fired Boiler," Shanghai Jiao Tong University, 2008.

[5] L. Wang, “A Critical Review on Additives to Reduce Ash Related Operation Problems in Biomass Combustion Applications,” Energy Procedia, Vol. 20, 2012, pp. 20-29. doi:10.1016/j.egypro.2012.03.004

[6] C. Ghenai and I. Janajreh, "CFD Analysis of the Effects of Co-firing Biomass with Coal," Energy Conversion and Management, 2010, Vol. 51, No. 8, pp. 1694-1701. doi:10.1016/j.enconman.2009.11.045

[7] H. X. Wu, H. B. Li and Z. L. Zhao, "Thermogravimetric analysis and Pyrolytic Kinetic Study on Coal/Biomass Blends," Journal of Fuel Chemistry and Technology, pp. 538-545.

[8] D. Eskilsson, "Optimisation of Efficiency and Emissions in Pellet Burners,” Biomass and Bioenergy, Vol. 27, No. 6, 2004, pp. 541-546.

doi:10.1016/j.biombioe.2003.09.008

[9] R. Scharler and I. Obernberger, "Numerical Modeling of Biomass Grate Furnace," Proceeding of 5th European conference on industrial furnaces and boilers, Porto, Portugal, 2000.

[10] M. Miltner, A Makaruk, M. Harasek and A. Friedl, "CFD-modeling Fort The Combustion of Solid Baled Biomass,” Fifth international conferdence on CFD in the Process Industrie, Melbourne, Austria, 2006.

[11] Y. B. Yang, "Mathematical Modelling of Straw Combustion in a 38 MWe Power Plant Furnace and Effect of Operating Conditions,” Fuel, Vol. 86, No. 1-2, 2007, pp. 129-142.doi:10.1016/j.fuel.2006.06.023

[12] X. Zhang, "Experimental Investigation and Mathematical Modelling of Wood Combustion in a Moving Grate Boiler,” Fuel Processing Technology, Vol. 91, No. 11, 2010, pp. 1491-1499. doi:10.1016/j.fuproc.2010.05.026

[13] J. Pprteiro, J. Collazo, D. Patino, J. C. M. Gonzalez and L. Miguez, "Numerical Modeling of a Biomass Pellet Domestic Boiler," Energy Fuels, Vol. 23, 2009, pp. 1067-1075.doi:10.1021/ef8008458

[14] C. Yin, L. Rosedahl, S. K. Kaer, C. Sonnik, S. L. Hvid and T. Hille, "Mathematical Modeling and Experimental Study of Biomass Combustion in a Thermal $108 \mathrm{MW}$ Grate-Fired Boiler,” Energy Fuels, Vol. 22, 2008, pp. 1380-1390.doi:10.1021/ef700689r

[15] J. Chaney, H. Liu and J. Li, “An Overview of CFD Modelling of Small-scale Fixed-bed Biomass Pellet Boilers with Preliminary Results from a Simplified Approach," Energy Conversion and Management, Vol. 63, 2012, pp. 149-156. doi:10.1016/j.enconman.2012.01.036 